\title{
Moulding of carbon fiber reinforced polycarbonate using unidirectional tapes
}

\author{
M. Shinohara ${ }^{1}$, S. Isshiki ${ }^{2}$, Y. Fukushima ${ }^{2}$, T. Katayama ${ }^{2}$ \\ \& K. Tanaka ${ }^{2}$ \\ ${ }^{1}$ Maizuru National College of Technology, Japan \\ ${ }^{2}$ Doshisha University, Japan
}

\begin{abstract}
Carbon fiber reinforced plastics (CFRP) are attracting attention in the automotive industry due to their light weight. Thermoset plastics like epoxies are mainly used as matrices of CFRP in that industry. The curing time of the thermosetting resin is long thus leading to poor productivity. Within thermoplastic resins, polycarbonate (PC) is excellent for its impact properties; consequently, it is expected to be used as the matrix of composite materials for automotive structures. Moreover, in order to obtain outstanding strength, the application of continuous fibers as reinforcement is anticipated. However, large-scale equipment is needed and the work of press load is required in order to impregnate PC into continuous fibers. Recently, unidirectional (UD) tapes of $\mathrm{CF} / \mathrm{PC}$ in which the PC matrix was impregnated into a $\mathrm{CF}$ bundle have been developed. In this study, carbon fiber reinforced polycarbonate (CF/PC) was moulded using UD tapes and the practicality of UD tape was examined by studying its mechanical properties aiming at shortening the moulding time.
\end{abstract}

Keywords: carbon fiber, polycarbonate, CFRTP, UD tape, plain weave, noncrimp fabric.

\section{Introduction}

Carbon fiber reinforced plastics (CFRPs) have advantages in relation to highspecific strength and high-specific modulus, hence the demand for CFRPs is increasing in the aerospace, automotive and sports industries [1-8]. Especially, thermoset plastics like epoxies are mainly used as matrices in CFRPs for the automotive industry. FRP using a thermosetting resin has low productivity, and it 
cannot be melted or reformed after moulding, making recycling difficult. Moreover, carbon fiber reinforced thermoplastic (CFRTP) is recyclable, has high productivity and impact strength; thus it is expected to be widely applied within the industry. Therefore it is appropriate to use CFRTPs when CFRPs are used in automotive applications [9]. Furthermore, it is necessary to choose a matrix excellent in strength, impact resistance and heat resistance when using CFRTP as automotive material. In order to obtain outstanding strength, the application of continuous fibers as reinforcement is also expected.

Polycarbonate (PC) has high impact strength compared to other plastics, thus it is expected to be used as the matrix in a CFRTP. However, large-scale equipment is needed and a higher press load is required in order to impregnate PC into continuous fibers [10]. Recently, unidirectional (UD) tapes of carbon fiber reinforced polycarbonate $(\mathrm{CF} / \mathrm{PC})$ in which the $\mathrm{PC}$ matrix was impregnated into $\mathrm{CF}$ bundles have been developed. In this study, $\mathrm{CF} / \mathrm{PC}$ was moulded using two kinds of semi products, namely plain weave and sheet stacking, which were both made with UD tapes and their mechanical properties were evaluated.

\section{Materials and experimental procedure}

\subsection{Materials}

UD tapes (Teijin Chemicals Ltd., Japan) of impregnated CF with PC were used. The width of the UD tape was $7.5 \mathrm{~mm}$ and its $V_{f}$ was $40 \%$. Two kinds of specimens were prepared using UD tapes. One was moulded by processing the UD tapes into a plain weave. Hereafter, this $\mathrm{CF} / \mathrm{PC}$ moulding is designated $\mathrm{CF} / \mathrm{PC}$ (plain weave: UD). For the preparation of the other one, the UD tapes were arranged unidirectionally; then, it was fabricated one layer at a time in the shape of a sheet and moulded by laminating at $0^{\circ} / 90^{\circ}$. This CF/PC specimen is designated $\mathrm{CF} / \mathrm{PC}$ (sheet: UD). A specimen using non-crimp fabric (NCF) was also prepared for comparison. For the non-crimp stitched carbon fabric (NCF, $\left.300 \mathrm{~g} / \mathrm{m}^{2},\left[0^{\circ} / 90^{\circ}\right]\right)$, PAN-based carbon fibers, stitched together by polyester sewing thread, were used as the reinforcing fibers and PC films (PC-2151, Teijin Chemicals Ltd., Japan) as the matrix. This $\mathrm{CF} / \mathrm{PC}$ specimen is called CF/PC (NCF).

\subsection{Moulding process}

For moulding specimens using NCF, the optimal conditions of previous research were adopted [11]. Specimens were moulded by a high-speed compression moulding process (referred to as IH system) using an electromagnetic induction system [11]. Kapton ${ }^{\circledR}$ film (200H, Du Pont-Toray Co., Ltd., Japan) was used as a vacuum bag. After putting the material inside the vacuum bag, the inner pressure was reduced to under $1 \mathrm{kPa}$ before and during moulding by a vacuum pump. All moulding conditions are shown in table 1 . Cross sections of the specimens were observed by scanning electron microscope (SEM, SEM-6390LT, JEOL Ltd., Japan) for evaluating resin impregnation. 
Table 1: Moulding conditions of CF/PC.

\begin{tabular}{|c|c|c|c|c|c|}
\hline Specimens & $\begin{array}{c}\text { Maximum } \\
\text { Temperature } \\
{\left[{ }^{\circ} \mathrm{C}\right]}\end{array}$ & $\begin{array}{c}\text { Pressure } \\
{[\mathrm{MPa}]}\end{array}$ & $\begin{array}{l}\text { Holding time } \\
\text { at maximum } \\
\text { temperature } \\
{[\mathrm{s}]}\end{array}$ & Vacuum & $\begin{array}{c}V_{f} \\
{[\%]}\end{array}$ \\
\hline $\begin{array}{c}\text { CF/PC } \\
\text { (plain } \\
\text { weave: } \\
\text { UD) }\end{array}$ & 300 & \multirow{3}{*}{6} & 90 & \multirow[t]{2}{*}{$\begin{array}{l}\text { Without } \\
\text { vacuum }\end{array}$} & \multirow{3}{*}{40} \\
\hline $\begin{array}{c}\mathrm{CF} / \mathrm{PC} \\
\text { (sheet: UD) }\end{array}$ & 280 & & 30 & & \\
\hline $\begin{array}{l}\mathrm{CF} / \mathrm{PC} \\
(\mathrm{NCF})\end{array}$ & 300 & & 150 & $\begin{array}{l}\text { Vacuum } \\
\text { assisted }\end{array}$ & \\
\hline
\end{tabular}

\subsection{Evaluation of mechanical properties}

Three point bending tests were conducted on a universal material testing machine (5566, Instron, USA), following the recommended testing procedures as described in JIS-K7074.The dimensions of the specimens were set at $100 \times 15 \times 2 \mathrm{~mm}^{3}$. The specimen support span was $80 \mathrm{~mm}$. The cross-head displacement rate was set at $5 \mathrm{~mm} / \mathrm{min}$.

The drop weight impact tests were conducted using an instrumented drop weight impact test machine (IITM-18, Yonekura Co., Japan). The specimen configuration was of a regular octagonal shape of $25 \mathrm{~mm}$ in side length. The specimen was fixed using a suppression board with a hole of $40 \mathrm{~mm}$ in diameter; and a hemisphere of $10 \mathrm{~mm}$ in diameter was used as the striker. The mass of drop weight was $2.0 \mathrm{~kg}$. In order to apply a $7 \mathrm{~J}$ per $1 \mathrm{~mm}$ in specimen thickness, the height of drop weight was adjusted.

\section{Results and discussion}

\subsection{Evaluation of impregnation}

Fig. 1 shows the cross section of moulded CF/PC (plain weave: UD). Some voids were observed in fig. 1. Some cavities due to weaving of CF/PC (plain weave: UD) could be one reason for these voids. Fig. 2 shows the cross section of moulded CF/PC (sheet: UD). The number of voids in the CF/PC (sheet: UD) is far lower than that in $\mathrm{CF} / \mathrm{PC}$ (plain weave: UD). Fig. 3 shows the cross section of moulded $\mathrm{CF} / \mathrm{PC}(\mathrm{NCF})$. The impregnation in $\mathrm{CF} / \mathrm{PC}(\mathrm{NCF})$ is worse than in $\mathrm{CF} / \mathrm{PC}$ (sheet: UD). Due to the high viscosity of polycarbonate resin, in direct moulding using PC films, it is difficult to mould $\mathrm{CF} / \mathrm{PC}$ with good impregnation. 


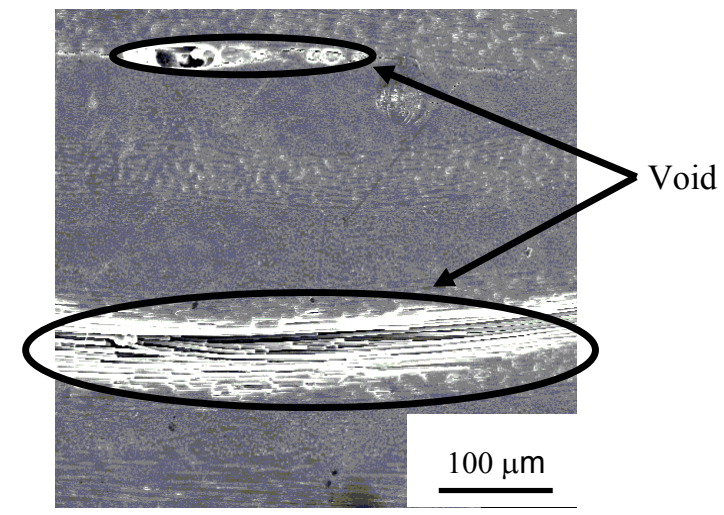

Figure 1: SEM observation of plain $\mathrm{CF} / \mathrm{PC}$ (plain weave: UD) cross section.

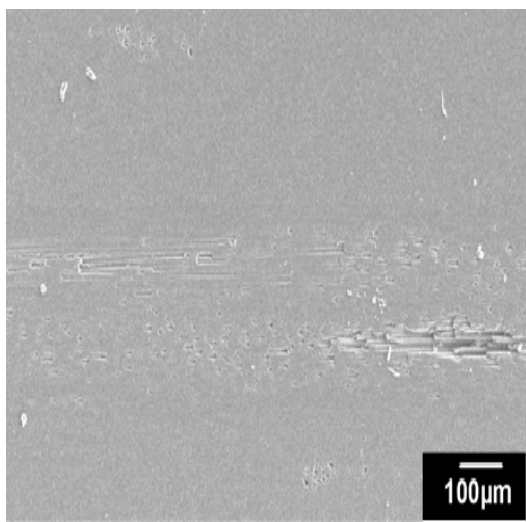

Figure 2: SEM observation of CF/PC (sheet: UD) cross section.

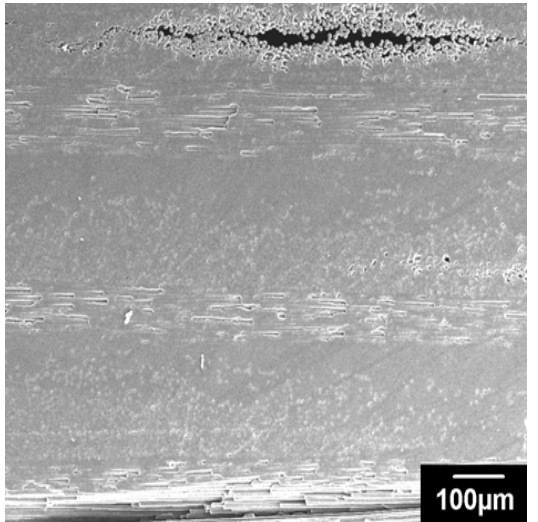

Figure 3: SEM observation of $\mathrm{CF} / \mathrm{PC} \quad(\mathrm{NCF})$ cross section.

\subsection{Results of three point bending tests}

The result of three-point bending testing of the CF/PC (plain weave: UD), CF/PC (sheet: UD) and $\mathrm{CF} / \mathrm{PC}$ (NCF) are shown in figs 4 and 5. According to figs 4 and 5 , it seems that there is a remarkable difference between $\mathrm{CF} / \mathrm{PC}$ (plain weave: UD) and CF/PC (sheet: UD). Fig. 6 shows the behaviour of the CF/PC (plain weave: UD) specimen under bending. The large standard deviation in the results of $\mathrm{CF} / \mathrm{PC}$ (plain weave: UD) shown in fig. 5 is due to the difference in the fractured position of the outermost layer of the specimen. When the fractured position was in between UD tapes, the specimens fracture at low stress. On the other hand, when the fractured position was in the UD tape, the bending strength was high. According to figs 4 and 5, the bending strength of the CF/PC (sheet: 


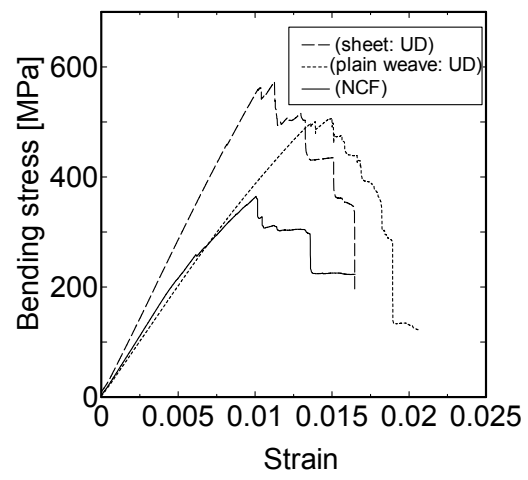

Figure 4: Stress-strain curves from the three point bending tests.

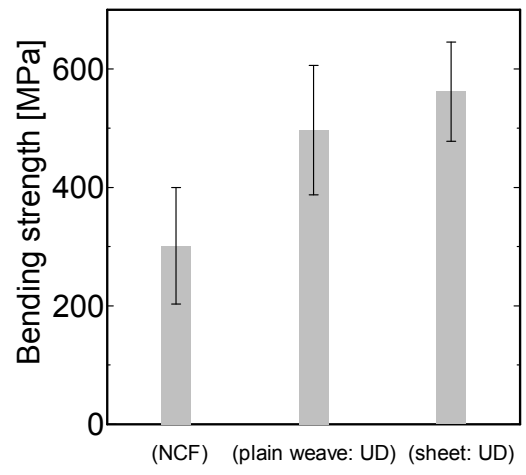

Figure 5: Bending strength.

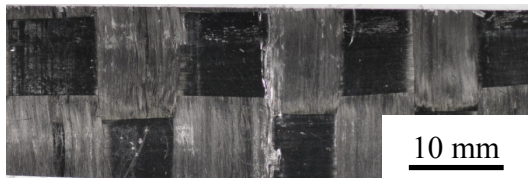

(a) Fractured position between UD tapes

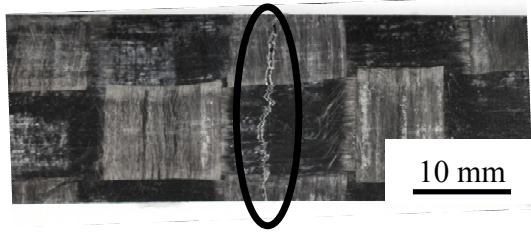

(b) Fractured position within a UD tape

Figure 6: $\mathrm{CF} / \mathrm{PC}$ (plain weave: UD) specimen under bending. 
UD) is high and its standard deviation is small. Fig. 7 shows the behaviour of the $\mathrm{CF} / \mathrm{PC}$ (sheet: UD) specimen under bending. In addition, the CF/PC (sheet: UD) fractured at the centre of specimen; this is very much unlike the $\mathrm{CF} / \mathrm{PC}$ (plain weave: UD). The results for the flexural modulus of $\mathrm{CF} / \mathrm{PC}$ (plain weave: UD), $\mathrm{CF} / \mathrm{PC}$ (sheet: UD) and $\mathrm{CF} / \mathrm{PC}(\mathrm{NCF})$ are shown in fig. 8. The flexural modulus of $\mathrm{CF} / \mathrm{PC}$ (plain weave: UD) is lower than that of CF/PC (NCF). This is because the flexural modulus is governed by fiber orientation. Moreover, the larger standard deviation in the bending strength of CF/PC (NCF) comes from the poor impregnation of polycarbonate resin into carbon fibers. Due to the poor impregnation, some tests on $\mathrm{CF} / \mathrm{PC}(\mathrm{NCF})$ specimens resulted in delamination fracture. The CF/PC (sheet: UD) has a higher bending strength and small standard deviation. The impregnation in CF/PC (sheet: UD) appears good compared to that in the other specimens.

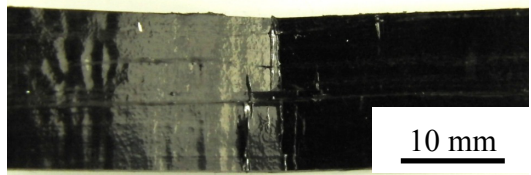

Figure 7: $\quad \mathrm{CF} / \mathrm{PC}$ (sheet: UD) specimen under bending.

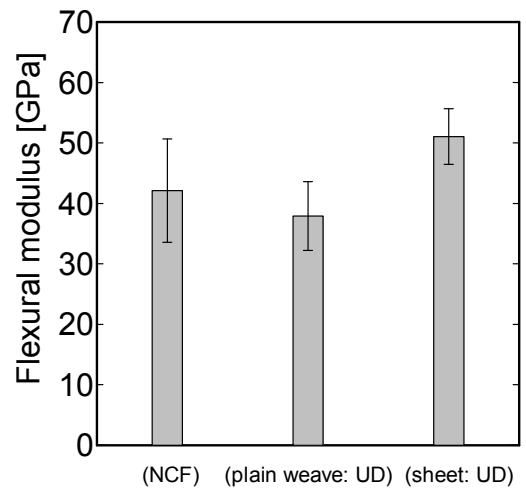

Figure 8: Flexural modulus.

\subsection{Results of drop weight impact test}

Fig. 9 shows the obtained load-displacement diagrams for $\mathrm{CF} / \mathrm{PC}$ (plain weave: $\mathrm{UD}), \mathrm{CF} / \mathrm{PC}$ (sheet: UD) and $\mathrm{CF} / \mathrm{PC}(\mathrm{NCF})$. Fig. 10 shows the maximum load for each specimen. Fig. 11 shows the absorbed energy-displacement diagrams for $\mathrm{CF} / \mathrm{PC}$ (plain weave: UD), $\mathrm{CF} / \mathrm{PC}$ (sheet: UD) and $\mathrm{CF} / \mathrm{PC}$ (NCF). Fig. 12 shows the absorbed energy for each specimen. According to figs 10 and 11 , $\mathrm{CF} / \mathrm{PC}$ (plain weave: UD) and CF/PC (sheet: UD) exhibit higher maximum load and absorbed energy than $\mathrm{CF} / \mathrm{PC}(\mathrm{NCF})$. Moreover, the characteristics of $\mathrm{CF} / \mathrm{PC}$ 


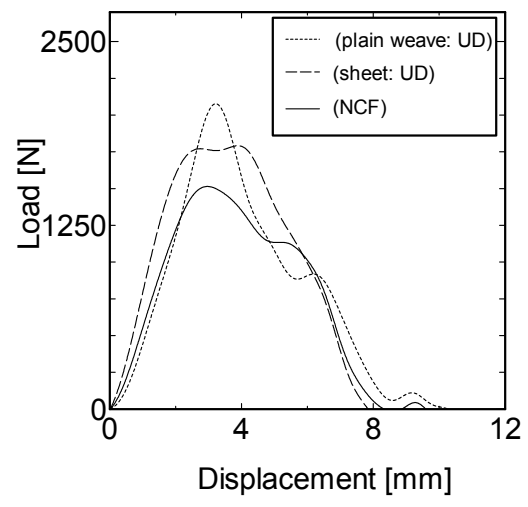

Figure 9: Load-displacement curves from drop weight impact test.

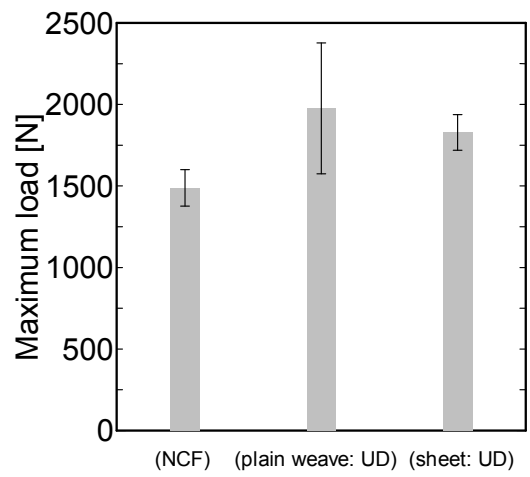

Figure 10: Maximum load from drop weight impact test.

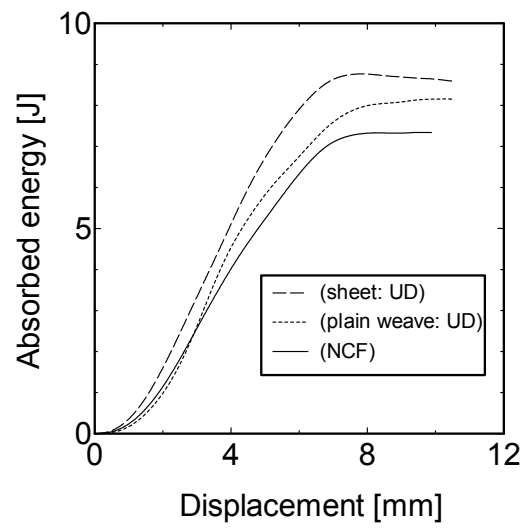

Figure 11: Absorbed energy-displacement curves from drop weight impact test. 


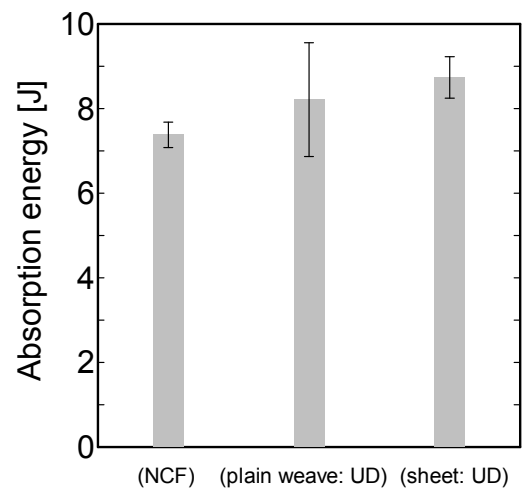

Figure 12: Absorbed energy from drop weight impact test.

(plain weave: UD) and $\mathrm{CF} / \mathrm{PC}$ (sheet: UD) is very different, although the same $\mathrm{UD}$ tapes were used. The maximum load for $\mathrm{CF} / \mathrm{PC}$ (plain weave: UD) is higher than that for CF/PC (sheet: UD). The CF/PC (sheet: UD) exhibit a constant load just beyond the maximum load. As with the three point bending test results, the statistical variability in the $\mathrm{CF} / \mathrm{PC}$ (plain weave: UD) is due to the difference in the fractured position part of the outermost layer of the specimen. When the fractured position was in between UD tapes, specimens fracture at low maximum load and absorbed energy. On the other hand, when the fractured position was in the UD tape, the bending strength was high.

\section{Conclusions}

In this study, carbon fiber reinforced polycarbonate $(\mathrm{CF} / \mathrm{PC})$ was moulded by using two kinds of semi product, plain weave and sheet stacking, that were made with UD tapes, and their mechanical properties were evaluated. The investigation yielded the following conclusions:

1. The CF/PC (sheet: UD) has the highest bending strength and bending modulus among the three kind of specimens. This is due to the good impregnation property of CF/PC (sheet: UD).

2. The maximum load from the drop weight impact tests on $\mathrm{CF} / \mathrm{PC}$ (plain weave: UD) is higher than that on $\mathrm{CF} / \mathrm{PC}$ (sheet: UD). The CF/PC (sheet: UD) exhibits a higher maximum load and absorbed energy than $\mathrm{CF} / \mathrm{PC}$ (NCF).

\section{Acknowledgements}

This study was partially supported as part of the High Technological Research Project at the Research and Development Center for Advanced Composite Materials of Doshisha University and the Ministry of Education, Culture, Sports, Science and Technology, Japan. 


\section{References}

[1] Uotani, S., Yanagisawa, M. \& Itou, J., [title in Japanese]. Journal of the Japan Society for Composite Materials, 25(6), pp. 236-239, 1999.

[2] Nomaguti, K., [title in Japanese]. Journal of the Japan Society for Composite Materials, 32(3), pp. 100-112, 2006.

[3] Paesano, A., Cohee, D. \& Palmese, G.R., Carbon-fiber reinforced thermoplastic materials for rigidizable space systems. Journal of Thermoplastic Composite Materials, 16(2), pp. 139-170, 2003.

[4] Taki, T. \& Amaoka, K., [title in Japanese]. Journal of the Japan Society for Composite Materials, 24(2), pp. 41-48, 1998.

[5] Ishikawa, R., [title in Japanese]. Journal of the Japan Society of Polymer Processing, 17(5), pp. 294-299, 2005.

[6] Kimoto, Y., [title in Japanese]. Journal of the Japan Society for Composite Materials, 32(4), pp. 147-150, 2006.

[7] Huntley, M.P., Davis, C.L., Strangwood, M. \& Otto, S.R., Comparison of the static and dynamic behaviour of carbon fibre composite golf club shafts. Proceedings of the Institution of Mechanical Engineers Pt. L: Journal of Materials: Design and Applications, 220(4), pp. 229-236, 2006.

[8] Matsui, J., Reinforced Plastics, 44(11), pp. 458-465, 1998.

[9] Silverman, E.M. \& Forbes, W.C., Cost analysis of thermoplastic composites processing methods for spacecraft structures. SAMPE Journal, 26(6), pp. 9-15, 1990.

[10] Rezaei, F., Yunus, R., Ibrahim, N.A. \& Mahdi, E.S., Development of short-carbon-fiber-reinforced polypropylene composite for car bonnet. Polymer-Plastics Technology and Engineering, 47(4), pp. 351-357, 2008.

[11] Tanaka, K., Katayama, T. \& Uno, K., Eco-efficient manufacturing process for fibre reinforced thermoplastic. WIT Transactions on the Built Environment, 97, eds. W.P. De Wilde \& C.A. Brebbia, pp. 203-210, 2008. 